\title{
Effect of Simulated Aging Game versus Traditional Lecture on Nursing Students' Knowledge and Attitude towards Elderly
}

\author{
Nadia Mohamed Hassan Saleh, Lecturer \\ Gerontological Nursing, Faculty of Nursing, Mansoura University
}

Eman Baleegh Meawad Elsayed, Lecturer

Gerontological Nursing, Faculty of Nursing, Mansoura University

Heba Noshy Abd El-Aziz Mohamed, Lecturer

Gerontological Nursing, Faculty of Nursing, Mansoura University

\author{
Abdel-Hady El-Gilany, Professor \\ Public Health, Faculty of Medicine, Mansoura University
}

\begin{abstract}
Attitude of nursing students toward elderly tends to be negative. This attitude can be changed by increasing awareness of normal aging processes through simulated aging games. Objective: Determine the effect of simulated aging game versus traditional lecture on nursing students' knowledge and attitude towards elderly. Setting: This study was conducted in the Gerontological Nursing Department, Faculty of Nursing-Mansoura University. Subjects: A total number of 82 fourth year nursing students were included in the study. Tools: Three tools were used for data collection; Nursing Students' Socio-Demographic, and their Experience with Elderly Structured Interview Schedule, Kogan Attitudes towards Old People Scale (KAOP), and Nursing Students' Knowledge Related to Normal Physiological Changes Of Aging. Results: Significant differences in knowledge and attitude scores among students in the simulation group compared to those in the lecture group after the application of the simulation game. Conclusion: Simulation improves knowledge, and attitude of nursing students toward older adults than the traditional lecture. Recommendations: Simulation is an effective teaching method that enables students to improve their knowledge and attitude toward elderly.
\end{abstract}

Keywords: Simulation; Elderly; Knowledge; Attitude.

\section{Introduction}

Teaching about age related changes is an important foundation for improving knowledge and changing negative attitude towards elderly people. If the process of aging is not well understood by the care providers, the quality of care will definitely be affected ${ }^{(1)}$. The quality of care provided for elderly is being directly related to the attitude and knowledge of health care professional $^{(2)}$. Since the student nurse of today is the health care provider of tomorrow, so it is essential for nursing educators to prepare the students for their future work particularly with elderly people ${ }^{(3)}$.
Nursing student's attitudes toward working with elderly have a tendency to be negative ${ }^{(4-6)}$. In the light of these negative dispositions, many nursing students don't prefer to work with elderly after graduation and these negative attitudes will definitely influence the nature of care given to elderly ${ }^{(7,8)}$. Findings of previous studies concerning knowledge and attitudes of nurses toward the older people have been worrying and alarming and these studies also, pointed out that student nurses have developed stereotypes and do not desire to work with older people because they consider them passive, frustrating, boring, fragile, depressed, and useless ${ }^{(9-12)}$. Also some studies have reported that the majority of subjects have a negative attitude toward 
the normal changes of aging. They described elderly person as rigid, irritable, alone, and isolated ${ }^{(13-15)}$.

Other studies on the attitude and quality of care suggest that the more negative the attitude, the poorer the quality of care and this can lead to ageism, a process of stereotyping and discriminating against older people. Attempts to give high quality elder care must take into concern both the attitude of the nurses toward the older people and their knowledge of the aging process ${ }^{(9-11,16)}$.

Traditional lectures are widely used as a teaching method in the health sciences, they are often dull, deliver large amounts of information in short time periods, and promote passive processes of thinking ${ }^{(17)}$. Conversely, educational simulation games are innovative teaching tools that have been shown to promote critical thinking, provide the students with a new method of learning that uses both cognitive and affective learning, which may be easier for the student to remember and recall the content $^{(18)}$. Several simulation games have been utilized effectively with nursing students to increase their knowledge and attitude $^{(19-21)}$.

Simulation games are defined as competitive actions presided over by particular rules to achieve a specified goal $^{(22)}$. Also simulation refers to those activities that reflect the reality of a clinical environment. In other words, it includes activities such as role-playing, using interactive videotapes and mannequins that help students in learning .Using simulation ageing games in gerontological nursing courses has been effective for providing nursing students with more opportunities to understand the physiological changes of aging and enable students to build up their attitudes and capacities as they relate to work with elderly ${ }^{(23,24)}$. Simulation game is an effective method for teaching theoretical concepts, such as caring attitudes, by allowing students to be actively included in the learning activities to improve students' knowledge and attitudes toward older adults, and increase their motivation to care for old people ${ }^{(19,20,25)}$

Gerontological nursing education has the responsibility to decrease the ageism of nursing students and improve their knowledge level about aging through increasing and widespread using of simulation as a learning approach ${ }^{(27,28)}$.

\section{Aim of the Study}

The aim of this study is to determine the effect of simulated aging game versus traditional lecture on nursing students' knowledge and attitude towards elderly.

\section{Research Hypotheses:}

1. Nursing students who receive aging simulation game exhibit high level of knowledge related to the elderly people than those who receive the lecture.

2. Nursing students who receive aging simulation game will exhibit positive attitude towards elderly than those who receive the lecture?

\section{Materials and Method}

\section{Materials}

Design: Randomized controlled trial research design was used.

Setting: This study was conducted in the Gerontological Nursing Department, Faculty of Nursing-Mansoura University.

Subjects: The study subjects comprised all the fourth year nursing students who enrolled in the Gerontological Nursing course during the academic year 2016/2017, it is a credit hours course. It includes 2 hours/ week for theoretical content, and 2 hours /week for clinical practice for a period of 14 weeks. Their number amounted to 100 nursing students, of these 82 nursing students were included in the study. Non respondent 18 students refuse to participate in the study. 
Students were allocated to two groups by block randomization; each block included ten students who were randomly allocated to either the simulation or lecture group (41 students in each group). Block randomization is commonly used in the two intervention situations where sample sizes for the two interventions are to be equal or approximately equal (each group has the same characteristics) The process involves recruiting participants in short blocks and ensuring that half of the participants within each block are allocated to intervention " $A$ " and the other half to "B".

Tools:

Three tools were used for data collection:

Tool I: Nursing Students' Sociodemographic, and their Experience With Elderly Structured Interview Schedule

This tool was developed by the researchers and included two parts:

- Part I: It included socio-demographic characteristics of the students such as age, sex, marital status and academic year.

- Part II: It included previous experience with older people e.g. (family members, relatives, neighbors and during clinical experience) and their source of knowledge about elderly e.g. (family, geriatric medicine course, friends, and mass media).

Tool II: Kogan Attitudes towards Old People scale (KAOP)

This scale was developed by Kogan $(1961)^{(29)}$. It comprises 17 coordinated match statements, each with a positive and negative components, on a six point Likert scale ranging from strongly agree to strongly disagree. This scale was translated into Arabic language and modified by Zakari (2005) according to this modification the study subjects reactions are scored using 5 point-Likert scale to be suitable for Arab society ${ }^{(30)}$. The negative statements were coded in the reverse. Odd and even statements were considered as negative and positive attitude respectively. The total score of the scale ranged between 34 to 170 . The higher score on the positive statements (score of all positive items) indicates a favorable disposition towards older people. While a higher scores on the negative items (score of all negative items) represent unfavorable disposition. The reliability was assured by means of Cronbach's alpha $\mathrm{r}=0.72$.

Tool III: Nursing Students' Knowledge related to Normal Physiological Changes of Aging

This tool was developed by the researchers after reviewing the related literature to assess knowledge of nursing students about normal age related changes. It included questions about normal physiological changes of aging such as changes in the integumentry, gastrointestinal and respiratory systems. In addition to, the sensory and mobility changes that older adults may experience. The total number of questions are (28), each correct answer is given a score of one (1) and wrong or no answer is given a score of zero (0). The total score is 28 .

\section{Method}

- Official permission was obtained from the Vice Dean for Education and Student Affairs-Faculty of Nursing Mansoura University after clarifying the aim of the study.

- Study tools were checked for content validity by five experts in the related fields of gerontological and community nursing.

- A pilot study was carried out on 10 nursing students who refused to participate in the study, to test and ascertain the clarity, feasibility and applicability of the tools. Modifications were done accordingly.

- Pre test was done for all fourth year nursing students who participated in the study using the study tools. The pre test took 30 to 45 minutes. 
- Students in the simulation group were taught about the normal physiological changes using illustrative videos and simulation game (role play). While those in the lecture group received the content through the traditional method using power point presentation.

- The application of the simulation game started with the simulation group after their clinical time using simulation equipment such as (Cane, walker, wheelchair, eyeglasses, yellow cellophane, different colors of pins, gloves, cotton, and jar).

\section{Lecture group:}

Students in the lecture group received two lectures about normal physiological changes of aging through the traditional method using power point presentation.

\section{Session 1 (total 2 hours) Normal physiological changes of aging:}

The session included description of normal physiological changes affecting different body systems as integumentary, musculoskeletal, gastrointestinal, urinary and cardiovascular.

\section{Session 2 (total 2 hours) Normal physiological changes of aging:}

The session included description of normal physiological changes affecting different body systems as nervous, reproductive and sensory changes of vision, hearing, touch and smell.

\section{Simulation group:}

Students in simulation group received four sessions using illustrative videos about normal changes of aging and simulation games (role-play).

\section{Session 1 (total 2 hours) Normal physiological changes of aging:}

The session included description of normal physiological changes affecting different body systems as integumentry, musculoskeletal, gastrointestinal, urinary and cardiovascular. Using illustrative videos.

\section{Session 2 (total 2 hours) Normal physiological changes of aging:}

The session included description of normal physiological changes affecting different body systems as nervous, reproductive and sensory changes of vision, hearing, touch and smell. Using illustrative videos.

\section{Session 3 (Total 3 hours) Application of the simulation game (sensory changes):}

- The students were divided into four groups, with ten students in each group. The students in each group were divided into teams A and B. Student in team A played the role of the elderly, and those in $B$ acted as caregivers under the supervision of the researchers.

- Each of the four groups was assigned to one of the research members who was responsible for the application of the game at the same time in different classes.

- Illustrative video about simulation game was used to explain the steps to be followed in the simulation game to enhance students understanding of the game (which took one hour).

- Instructions were given to the students before they started the game, students in group A were asked to use the appropriate simulation equipments, to simulate (role play) the normal changes that older adults experience and students in group B assigned the role of the caregiver providing the necessary assistance for group A members. Then students switched the roles with each other.

- The third session included the following activities to help the students experience some of the sensory changes that older peoples develop such as ${ }^{(31)}$ :

\section{Taste Simulation:}

Give each student unsalted crackers, then ask him to drink unsweetened juice without sugar to experience changes in taste which elder feel as a result of 
decreased number of taste buds with aging. Then ask the students to eat the cracker without chewing to experience chewing problems resulting from changes in dentition associated with old age.

\section{Smell Simulation:}

Hold the nostrils with finger and use foods similar in surface as apples and carrots, cut in small pieces and give them to the students while they close their eyes and ask them to try to identify the different taste.

\section{Sight Simulation:}

Use pieces of yellow cellophane and put them on the eyeglass, ask the student to wear it then try to select the white pin from pins of different colors; this helped the student to experience the decrease in visual acuity associated with old age.

\section{Hearing Simulation:}

Give cotton balls or mechanical ear plugs to each student and ask him to put it in their ears, then order the student to perform specific activities, this request aims that the student delineate how diminish in hearing acuity may influence how quick the elderly fulfills a given instructions.

\section{Touch Simulation:}

Wear a surgical glove and wrap tape around the tips of the fingers, try to differentiate between hot and cold water. It is more difficult because the pain threshold is increased and reaction time is slower among the elderly.

\section{Session 4 (Total: 3 hours) Application of the simulation game (Mobility and balance changes):}

This session included the following activities to help the students experience some of the normal changes that older peoples develop in the mobility and balance associated with age such as ${ }^{(31)}$ :

\section{Mobility and balance simulation:}

\section{Experience 1:}

- Immobilize the knee and elbow joints by wrapping them with elastic bandages. Use either the cane, or walker or the wheelchair and ask the student to go to the bathroom open the door, walk through and wash their hands.

- In order to experience the changes that occur in the mobility and balance the student were asked to climb the stairs using cane and walk in the corridors while using the walker or the wheelchair. Student B assist student A to maintain their safety. Then students switched the roles with each other.

\section{Experience 2:}

- Wrap covering tape around each finger of one hand, especially the thumb and index finger. Ask the student to tape a few fingers together to represent a stiffening joint. Then ask the student to try to open a jar, try to button or unbutton a coat and open a water faucet.

\section{Evaluation of the simulation game:}

- Evaluation of knowledge about normal physiological changes and attitude toward elderly was done immediately for both groups at the end of sessions using the study tools (tool II; Kogan Attitudes towards Old People Scale, and tool III; Nursing Students' Knowledge related to Normal Physiological Changes of Aging).

- Data collection started from 20 February 2017 till the 28 March 2017.

\section{Ethical considerations:}

- Approval of the research ethics committee

- Informed consent from the students was obtained after explanation of the purpose of the study

- All students participated voluntary and had the flexibility to withdraw from the study at any time, privacy and autonomy were assured. 


\section{Statistical Analysis}

Data were fed to the computer and analyzed using IBM SPSS software package version 20.0. Qualitative data were described using number and percent. Quantitative data were described using range (minimum and maximum), mean, and standard deviation. Significance of the obtained results was judged at the 5\% level.

The tests used were:

- Chi-square test: For categorical variables, to compare between different groups

- Fisher's Exact or Monte Carlo correction: Correction for chi-square when more than $20 \%$ of the cells have expected count less than 5 .

\section{Results}

Table (1) shows the distribution of nursing students' according to their sociodemographic characteristics and experience with old people in both groups. It was observed from the table that the age of the studied students ranged between 21 to 23 years with a mean of $21.6 \pm 0.5$ years for students in the simulation group, compared to $21.5 \pm 0.6$ years for those in the lecture group. Female constituted $78.0 \%$ and 82.9 $\%$ of students in the simulation and the lecture group respectively. Regarding marital status $85.4 \%$ and $90.2 \%$ of students in simulation and the lecture group respectively were single. As regards family income, $70 \%$ and $80 \%$ of students in simulation and control group respectively reported having enough income. No statistically significant difference was observed between both groups regarding all socio-demographic characteristics. About $85.5 \%$ of students in the simulation group and $87.8 \%$ in the lecture group had previous contact with elderly. Nearly $41.5 \%$ and $43.9 \%$ of students in the simulation and lecture group respectively live with elderly persons. $90.2 \%$ of students in the simulation group and $82.9 \%$ in the lecture group reported that they have knowledge about caring for old people. For students in both groups the main source of knowledge was the family, they represented $48.8 \%$ and $65.9 \%$ in simulation and the lecture group respectively.

Table (2) Comparing the effect of aging simulation game versus traditional lecture on the total mean score of knowledge of nursing students about normal aging changes among simulation and lecture groups. It can be observed from the table that, before the application of the simulation game the total mean score of knowledge of students about normal physiological changes of aging in the simulation group was $13.3 \pm 3.3$ and $13.0 \pm 3.6$ in the lecture group and the difference is not statistically significant. After the application of simulation game the total mean score of knowledge of students in the simulation group markedly improved 21.0 \pm 2.6 , compared to slightly improvement $16.4 \pm 3.5$ in the lecture group and the difference is statistically significant $(\mathrm{P}=0.001)$.

Table (3) Comparing the effect of aging simulation game versus traditional lecture on the total mean score of attitude of nursing students toward elderly among simulation and lecture groups. It can be observed that before the application of the simulation game the Positive attitude subscale total mean score was $53.7 \pm 5.7$ and $54.7 \pm 5.8$ among the students in simulation and lecture groups respectively, while after the application of the simulation game the positive attitude increased to $57.8 \pm 7.0$ among the simulation group, compared to $55.7 \pm 7.8$ in the lecture group and the difference is not statistically significant $(\mathrm{t}=1.3, \quad \mathrm{P}=0.2)$. The negative attitude subscale total mean score of students before application of the simulation game was $49.8 \pm 7.1$ among simulation group and $48.2 \pm 7.1$ in lecture group; after the application of the aging game the negative attitude decreased to $43.9 \pm 8.1$ among the simulation group, while it remained the same 48.2 \pm 7.3 in the lecture group and the difference is statistically significant $(\mathrm{p}=0.014)$. 
Table (4) shows the correlation coefficient between knowledge and attitude scores between both groups. It is noticed that no statistically significant correlations was observed between total knowledge score and attitude among students' in simulation and lecture groups before and after application of the simulation game.

\section{Discussion}

Increased knowledge about age related changes, and understanding the attitudes toward elderly is the main focus of the simulated aging experiences ${ }^{(32)}$. It would be difficult for nurses to provide quality care for older adults without this understanding ${ }^{(26)}$.

Better nursing education requires changes in the method of teaching in order to enhance students learning simulation games are one of the most widespread learning approach used with students. Therefore, this study was conducted to determine the effect of the simulated aging game versus traditional lecture on nursing students' knowledge and attitude towards elderly. The present study reported homogeneity between the students in both groups with no statistical significant difference between them (Table 1).

Participation in aging simulation activity appeared to be helpful to nursing students in increasing their knowledge, awareness about aging and understanding of the problems that older adults face ${ }^{(33)}$. The present study indicated a significant effect of aging simulation games on nursing students' knowledge about normal physiological changes of aging (table 2). This difference in results is explained by the fact that learning by doing and role-play enhance learning compared with the superficial responses obtained from traditional lectures. This result comes in congruent with $\mathrm{Yu}$ and Chen (2012) who indicated a significant increase in knowledge about aging after using the simulation $^{(26)}$. Another study conducted by Hong (2014), reported that ageing simulation games seemed effective in improving knowledge about gerontology ${ }^{(34)}$. Also the result of the present study is in accordance with some studies, which stated that simulation has a significant effect on knowledge ${ }^{(24,35-39)}$. Moreover, several studies indicated that lectures are not suitable for all types of learning styles and student studies ${ }^{(40,41)}$. Other studies even believe that lecture is boring and nonstimulating due to their uninvolved nature $^{(42,43)}$. In contrary Alfarah et al. (2010) reported that simulation games are not effective interventions for geriatric education $^{(44)}$. In addition, some studies have reported that traditional lecture format was found to be more effective than simulation game $^{(45-47)}$.

The simulation learning activity aims to change attitudes by having students personally experience age related changes affecting old people such as decrease in hearing and vision acuity, changes in the mobility, balance and stiffens of joints. ${ }^{(48,49)}$. Also, the present study results reported an improvement after the application of the simulation game in positive attitude and decreased in the negative attitude toward elderly in the simulation group than the lecture group (Table 3). This is in congruent with the study done by Henry et al. (2007) who indicated that most students had a positive attitude toward elderly after application of the game ${ }^{(33)}$. Another study done by lee et al. (2015) reported that negative attitude decreased significantly after simulation in the study group ${ }^{(50)}$. Also Yu et al. (2012) reported that attitudes toward elderly in the study group improved significantly after the application of the game ${ }^{(26)}$. In addition, other studies reported the same results ${ }^{(51,52)}$. In contrast, other studies contradicting the present study results which reported that nurses did not have more-positive attitudes about the care of older adults after application of simulation game ${ }^{(53-55)}$. Possible explanations for this contradiction might be that these studies were done on nurses working with elderly and they may be exhausted by the heavy care demands of 
the older adults, causing a less-positive attitude toward the elderly.

The present study results reported no significant correlation between knowledge and attitude of nursing students in both groups before and after application of the simulation (Table 4). This result is in contradiction with a study conducted by Lambrinou et al. (2009) who reported a statically significant correlation between knowledge and attitude of nursing students $^{(56)}$. This may be because the contradicted study involved all the lectures in gerontological course, which allow the students to acquire more knowledge about aging that may affect their attitude toward elderly; on the other hand, the present study included only one lecture (physiological changes) rather than all the content of gerontological nursing course.

\section{Conclusion}

Based on findings of the present study, it can be concluded that aging simulation game resulted in increased knowledge and decreased the negative attitudes of nursing students toward elderly in simulation group than lecture group.

\section{Recommendations}

- The simulation games should be used as an effective teaching method that improve knowledge and attitude of nursing students toward elderly.

- Further researches exploring the effect of simulation on different learning program is required to confirm the importance of the simulation games on student's development.

\section{Acknowledgement}

Sincere appreciation is directed to all fourth year nursing students for their cooperation and role during application of the aging simulation game. 
Table (1): Distribution of nursing students' according to their socio- demographic characteristics and experience with old people in both groups

\begin{tabular}{|c|c|c|c|c|c|}
\hline \multirow[t]{2}{*}{ Item } & \multicolumn{2}{|c|}{$\begin{array}{c}\begin{array}{c}\text { Simulation } \\
\text { group }\end{array} \\
\end{array}$} & \multicolumn{2}{|c|}{$\begin{array}{c}\text { Lecture } \\
\text { group }\end{array}$} & \multirow[t]{2}{*}{ Significance } \\
\hline & $N(41)$ & $\%$ & $\mathbf{N}(41)$ & $(\%)$ & \\
\hline Age $($ Mean \pm SD $)$ & \multicolumn{2}{|c|}{$21.6 \pm 0.5$} & \multicolumn{2}{|c|}{$21.5 \pm 0.6$} & $\mathrm{t}=0.2, \mathrm{P}=0.8$ \\
\hline $\begin{array}{l}\text { Sex: } \\
\text { Female } \\
\text { Male }\end{array}$ & $\begin{array}{c}32 \\
9\end{array}$ & $\begin{array}{l}78.0 \\
22.0\end{array}$ & $\begin{array}{c}34 \\
7\end{array}$ & $\begin{array}{l}82.9 \\
17.1\end{array}$ & $\begin{array}{l}\mathrm{P}=0.6 \\
\chi^{2}=0.3\end{array}$ \\
\hline $\begin{array}{l}\text { Marital status: } \\
\text { Single } \\
\text { Married }\end{array}$ & $\begin{array}{c}35 \\
6 \\
\end{array}$ & $\begin{array}{l}85.4 \\
14.6\end{array}$ & $\begin{array}{r}37 \\
4 \\
\end{array}$ & $\begin{array}{c}90.2 \\
9.8\end{array}$ & $\begin{array}{l}\mathrm{P}=0.7 \\
\chi^{2}=0.5\end{array}$ \\
\hline $\begin{array}{l}\text { Family Income: } \\
\text { Enough } \\
\text { Enough \& save } \\
\text { Not enough }\end{array}$ & $\begin{array}{c}32 \\
5 \\
4\end{array}$ & $\begin{array}{c}78.0 \\
12.2 \\
9.8\end{array}$ & $\begin{array}{c}35 \\
3 \\
3\end{array}$ & $\begin{array}{c}85.4 \\
7.3 \\
7.3\end{array}$ & $\begin{array}{c}\text { Monte Carlo test, } \\
\mathrm{P}=0.7\end{array}$ \\
\hline $\begin{array}{l}\text { Experience with old people: \# } \\
\text { Previous contact } \\
\text { Living with elderly person } \\
\text { Caring for old people }\end{array}$ & $\begin{array}{l}35 \\
17 \\
37 \\
\end{array}$ & $\begin{array}{l}85.5 \\
41.5 \\
90.2 \\
\end{array}$ & $\begin{array}{l}36 \\
18 \\
34 \\
\end{array}$ & $\begin{array}{l}87.8 \\
43.9 \\
82.9 \\
\end{array}$ & $\begin{array}{l}\chi^{2}=0.1, P=1.0 \\
\chi^{2}=0.1, P=1.0 \\
\chi^{2}=0.9, P=0.3\end{array}$ \\
\hline $\begin{array}{l}\text { Source of knowledge about elderly: \# } \\
\text { Family } \\
\text { Geriatric medicine course } \\
\text { Mass media } \\
\text { Friends }\end{array}$ & $\begin{array}{c}20 \\
16 \\
12 \\
7\end{array}$ & $\begin{array}{l}48.8 \\
39.0 \\
29.3 \\
17.1\end{array}$ & $\begin{array}{c}27 \\
11 \\
7 \\
31\end{array}$ & $\begin{array}{c}65.9 \\
26.8 \\
41.5 \\
7.3\end{array}$ & $\begin{array}{c}\chi^{2}=2.4, \mathrm{P}=0.12 \\
\chi^{2}=1.4, \mathrm{P}=0.2 \\
\chi^{2}=1.3, \mathrm{P}=0.2 \\
\chi^{2}=1.8, \mathrm{P}=0.3\end{array}$ \\
\hline
\end{tabular}

\# More than one answer

Table (2): Comparing the effect of aging simulation game versus traditional lecture on the total mean score of knowledge of nursing students about normal aging changes among simulation and lecture groups

\begin{tabular}{||l|c|c|c||}
\hline $\begin{array}{l}\text { Knowledge about } \\
\text { normal aging changes }\end{array}$ & $\begin{array}{c}\text { Simulation group (41) } \\
\text { Mean } \pm \text { SD }\end{array}$ & $\begin{array}{c}\text { Lecture group (41) } \\
\text { Mean } \pm \text { SD }\end{array}$ & Significance \\
\hline Pre- intervention & $13.3 \pm 3.3$ & $13.0 \pm 3.6$ & $\mathrm{t}=0.5, \mathrm{P}=0.6$ \\
Post- intervention & $21.0 \pm 2.6$ & $16.4 \pm 3.5$ & $\mathrm{t}=6.8, \mathrm{P} \leq 0.001$ \\
\hline Significance & $\begin{array}{c}\text { Paired } \mathrm{t}=13.6, \\
\mathrm{P} \leq 0.001\end{array}$ & $\begin{array}{c}\text { Paired } \mathrm{t}=5.5, \\
\mathrm{P} \leq 0.001\end{array}$ & \\
\hline
\end{tabular}

Significant at $\mathrm{p} \leq 0.05$ 
Table (3): Comparing the effect of aging simulation game versus traditional lecture on the total mean score of attitude of nursing students toward elderly among simulation and lecture groups

\begin{tabular}{|l|c|c|c||}
\hline $\begin{array}{l}\text { Attitude of nursing } \\
\text { students toward elderly }\end{array}$ & $\begin{array}{c}\text { Simulation group (41) } \\
\text { Mean } \pm \text { SD }\end{array}$ & $\begin{array}{c}\text { Lecture group (41) } \\
\text { Mean } \pm \text { SD }\end{array}$ & Significance \\
\hline $\begin{array}{l}\text { Positive attitude subscale } \\
\text { Pre- intervention. }\end{array}$ & $53.7 \pm 5.7$ & $54.7 \pm 5.8$ & $\mathrm{t}=1.9, \mathrm{P}=0.07$ \\
$\begin{array}{l}\text { Positive attitude subscale } \\
\text { Post intervention. }\end{array}$ & $57.8 \pm 7.0$ & $55.7 \pm 7.8$ & $\mathrm{t}=1.3, \mathrm{P}=0.2$ \\
\hline Significance & Paired $\mathrm{t}=1.1, \mathrm{P}=0.3$ & Paired $\mathrm{t}=1.2,0 \mathrm{P}=0.2$ & \\
\hline $\begin{array}{l}\text { Negative attitude subscale } \\
\text { Pre- intervention }\end{array}$ & $49.8 \pm 7.1$ & $48.2 \pm 7.1$ & $\mathrm{t}=0.99, \mathrm{P}=0.3$ \\
$\begin{array}{l}\text { Negative attitude subscale. } \\
\text { Post intervention }\end{array}$ & $43.9 \pm 8.1$ & $48.2 \pm 7.3$ & $\mathrm{t}=2.5, \mathrm{P}=0.014$ \\
\hline Significance & Paired $\mathrm{t}=3.5, \mathrm{P} \leq 0.001$ & Paired $\mathrm{t}=0, \mathrm{P}=1.0$ & \\
\hline
\end{tabular}

Significant at $\mathrm{p} \leq 0.05$

Table (4): Correlation coefficient between knowledge and attitude scores among simulation and lecture group

\begin{tabular}{||l|c|c|c|c||}
\hline & \multicolumn{2}{|c|}{ Simulation group } & \multicolumn{2}{c|}{ Lecture group } \\
\hline & Knowledge pre & $\begin{array}{c}\text { Knowledge } \\
\text { post }\end{array}$ & Knowledge pre & $\begin{array}{c}\text { Knowledge } \\
\text { Post }\end{array}$ \\
\hline $\begin{array}{l}\text { Total attitude } \\
\text { Pre }\end{array}$ & -0.2 & -0.3 & -0.1 & 0.3 \\
\hline $\begin{array}{l}\text { Total attitude } \\
\text { Post }\end{array}$ & -0.1 & -0.2 & -0.2 & 0.3 \\
\hline
\end{tabular}




\section{References}

1. Lee S. The Principles of geriatric care and aging. Taipei, Taiwan: Taiwan Association of Gerontology and Geriatrics. 2003. Available at: http://www.google.com. Retrieved on 12-4-2017.

2. Jacelon C. Attitude and behaviors of hospital staff toward elders in an acute care settings. Applied Nursing Research 2002; 15(4): 227-234.

3. Cozort R. Student nurses' attitudes regarding older adults: Strategies for fostering improvement through academia. Teaching and Learning in Nursing 2008; 3(1): 21-25.

4. Courtney M, Tong S, Walsh A. Acutecare nurses' attitudes towards older patients: A literature review. International Journal of Nursing Practice 2000; 6:62-69. Available at: http://www.google.com. Retrieved on: 20-5-2017.

5. Gallagher S, Bennett K, Halford J. A comparison of acute and long-term health-care personnel's attitudes towards older adults. International Journal of Nursing Practice 2006; 12: 273-279. Available at: http://www.google.com. Retrieved on: 12-5-2017.

6. McLafferty E. A comparison of nurse teachers and student nurses' attitudes toward hospitalized older adults. Nurse Education Today 2005o/op; 25: 472-479. Available at: http://www.google.com. Retrieved on: 17-4-2017.

7. McLafferty I, Morrison F. Attitudes toward hospitalized older adults. Journal of Advanced Nursing 2004; 47(4):446-453.

8. Schigelone A. How can we ignore the why? A theoretical approach to health care professionals' attitudes toward older adults. Journal of Gerontology Social Work 2003; 40(3): 31-50.

9. Herdman E. Challenging the discourse of nursing ageism. International Journal of Nursing Studies 2002; 39(1): 105 114.

10. Happell B, Brooker J. Who will look after my grandmother: attitudes of student toward the care of older adults? Journal of Gerontological Nursing 2001; 27(12): 12-17.

11. Soderhamn O, Lindencrona C, Gustavsson S. Attitudes toward older people among nursing students and registered nurses in Sweden. Nursing Education Today 2001; 21, 225-229.

12. Aud M, Bostick J, Marek K, McDaniel R. Introducing baccalaureate student nurses to gerontological nursing. Journal of Professional Nursing 2006; 22(2):73-78.

13. Cottle N, Glover R. Combating ageism: Change in student knowledge and attitudes regarding aging. Educ Gerontol 2007; 33:501-512 Available at: http://www.google.com. Retrieved on: 20-5-2017.

14. Gallagher S, Benntee K, Halford J. A comparison of acute and long term health care personnel's attitudes towards older adults. Int J Nurs Pract 2006; 12:273-279. Available at: http://www.google.com. Retrieved on: 14-2017.

15. Wang P, Yang K. An intergenerational learning interaction between elders as transmitters and young learners. J Natl Bingdong Educ Teach Coll 2010; 34:149-176. Available at: http://www.google.com. Retrieved on: 15-5-2017.

16. Huang C. Undergraduate students' knowledge about aging and attitudes toward older adults in east and west: a 
socio-economic and cultural exploration. International Journal of Aging Hum Dev 2013; 77(1): 59-76.

17. Shiroma P, Massa A, Alarcon R. Using game format to teach psychopharmacology to medical students. Medical Teacher 2011; 33(2): 156-160.

18. Strickland H, Kaylor S. Bring you're Agame: Educational gaming for student success. Nurse Education 2016; 40: 101-103. Available at: http://www.google.com. Retrieved on: 11-4-2017.

19. Bonstelle S, Govoni A. Into aging: Exploring aging through games. Rehabil Nurs 1984; 9(2): 23-27.

20. Bartfay W, Bartfay E. Promoting health in schools through a board game. West $\mathrm{J}$ Nurs Res 1994; 16:438-446. Available at: http://www.google.com. Retrieved on: 6-4-2017.

21. Rowles C, Brigham C. Strategies to promote critical thinking and active learning. In: Billings DM, J, Halstead A, eds. Teaching in Nursing: A Guide for Faculty. St. Louis, Mo 2005; 283-315. Available at: http://www.google.com. Retrieved on: 12-5-2017.

22. Pacala J, Boult C, Hepburn K. Ten years' experience conducting the aging game workshop: was it worth it? Journal of the American Geriatrics Society 2006; 54:144-149. Available at: http://www.google.com. Retrieved on: 12-4-2017.

23. Blakely G, Skirton H, Cooper S, Allum $\mathrm{P}$, Nelmes P. Use of educational games in the health professions: a mixed methods study of educators' perspectives in the UK. Nurs Health Sci 2010; 12:2732. Available at: http://www.google.com. Retrieved on: 15-2017.
24. Evans S, Lombardo M, Belgeri M, Fontane P. The Geriatric Medication Game in pharmacy education. Am J Pharm Educ 2005; 69(3): 304-310.

25. Cohen H, Sandel M, Thomas C. Using focus groups educational methodology: Deconstructing stereotypes and social work practice misconceptions concerning aging and older adults. Educ Gerontol 2004; 30:329-346. Available at: http://www.google.com. Retrieved on: $12-5-2017$.

26. Yu C, Chen K. Experiencing simulated aging improves knowledge of and attitudes toward aging. Journal of the American Geriatrics Society 2012; 60(5): 957-61.

27. King T. Helping baccalaureate nursing students care for the wellbeing of older adults. International Journal of Nursing Education Scholarship 2005; 2(1).

28. McLeary L, McGilton K, Boscart V, Oudshoorn A. Improving gerontology content in baccalaureate nursing education through knowledge transfer to nurse educators. Canadian Journal of Nursing Leadership 2009; 22(3): 33-46.

29. Kogan, N. Attitudes toward old people: the development of a scale and examination of correlates. Journal of Abnormal and Social Psychology 1961; 62(1): 44-54.

30. Zakari N. Attitudes toward the elderly and knowledge of aging as correlates to the Willingness and intention to work with elderly among Saudi nursing students. Published Ph.D. Dissertation, George Mason University 2005; Available at: http://proquest.umi.com.

31. Schmall, Staton. Illinois Teacher of Home Economics. "Understanding the Aging Process through Simulation," Volume XXV, No. 4. March/April (1982): University of Illinois, UrbanaChampaign 
32. Bradley P, Bligh J. Clinical skills centers: Where are we going? Medical Education 2005; 39: 649-50. Available at: http://www.google.com. Retrieved on: 21-4-2017.

33. Henry B, Douglass C, Kostiwa I. Effects of Participation in an aging game simulation activity on the attitudes of allied health students toward older adults. The Internet Journal of Allied Health Sciences and Practice 2007. Available at: http://www.google.com. Retrieved on: 32-4-2017.

34. Hong S. The impact of incorporating ageing simulation games into a module on social gerontology. CDTL Brief, First Look (Nov/Dec 2014). Available at: http://www.cdtl.nus.edu.sg/brief/firstloo k/pdf/HongSI.pdf.

35. Tawalbeh I, Tubaishat A. Effect of simulation on knowledge of advanced cardiac life support, knowledge retention and confidence of nursing students in Jordan. Journal of Nursing Education 2013; 52. Available at: http://www.google.com. Retrieved on: 12-4-2017.

36. Akhu Zaheya L, Gharaibeh M, Alostaz Z. Effectiveness of simulation on knowledge acquisition, knowledge retention, and self efficacy of nursing students in Jordan. Clinical Simulation in Nursing 2013; 9: 335-342. Available at: http://www.google.com. Retrieved on: $12-5-2017$.

37. Lin K. The influence of the attitude and behavior intention to the elderly of the nursing students after geriatric nursing program. J Natl Hungkuang Teach Coll 2005; 47:25-35. Available at: http://www.google.com. Retrieved on: 22-4-2017.

38. Shinnick M, Evangelista L. Predictors of knowledge gains using simulation in the education of pre licensure nursing students .J prof Nurs 2012; 28(1): 4147.

39. El Sayed F, Gad G. The Changes on Knowledge, Confidence and Skills accuracy of nursing students at a Simulated based setting versus Traditional during Neonatal Resuscitation. International Journal of Nursing 2015; 5: 4-7. Available at: http://www.google.com. Retrieved on: 12-4-2017.

40. Travis P, Simpson D, Steven D, Duthie E. Gaming Used as an Informal Instructional Technique: Effects on Learner Knowledge and Satisfaction. Journal of Surgical Education 2012; 69(3).

41. Charlier N, De Fraine B. Game-based learning as a vehicle to teach first aid content: A randomized experiment. Journal of School Health 2013; 83(7): 493-499.

42. Boeker M, Andel P, Vach W, Frankenschmidt A. Game-based elearning is more effective than a conventional instructional method (2013): A randomized controlled trial with third-year medical students. Journal Pone. Available at Available at: http://www.google.com. Retrieved on: 12-4-2017.

43. Swiderska, N, Thomason E, Hart A, Shaw, B. Randomized controlled trial of the use of an educational board game in neonatology. Medical teacher 2013; 35(5): 413-415.

44. Alfarah z, Holger J, Elie A. Educational games in geriatric medicine education: a systematic review. BMC Geriatrics 2010; 10:19.

45. Gibbs J, Trotta D, Overbeck A. Human patient simulation versus case study: Which teaching strategy is more effective in teaching nursing care for the 
hypoglycemic patient? Teaching and Learning in Nursing 2014; 9(2): 59-63.

46. -Gipson M, Bear M. Enhancing learning: a comparison of lecture and gaming outcomes. Nurse Educator 2013; 38(5): 184-185.

47. Selby G, Walker V, Diwakar V. A comparison of teaching methods: interactive lecture versus game playing. Medical Teacher 2007; 29(9-10): 972974.

48. Pacala J. Aging Game Manual. WilandBell Productions 2003: Available at: http://www.cinahl.com/cgi. Retrieved on: 12-4-2017.

49. McVey L, Davis D, Cohen H. The 'aging game 'an approach to education in geriatrics. JAMA 1989; 5;262(11): 1507-1509.

50. Lee Y, Shin S and Greiner P. Can education change attitude toward aging? A quasi-experimental design with a comparison group. Journal of nursing education and practice 2015; 5(9): 9099.

51. Varkey P, Chutka D, Lesnick T. The aging game: improving medical students' attitudes toward caring for the elderly.
Journal of the American Medical Directors Association 2006; 7: 224-229.

52. Lorraine V, Allen S, Lockett A, Rutledge C. Sensitizing students to functional limitations in the elderly: an aging simulation. Family medicine 1998; 30:15.

53. Hweidi I, Al-Obeisat S. Jordanian nursing students' attitudes toward the elderly. Nurse Educ Today 2006; 26:2330.

54. Lee C, Hsu H, Lee H. Effects of aging simulation program on nurses' attitudes and willingness toward elder Care. Taiwan Geriatric Gerontol 2016; 11(2): 105-115.

55. Jeong $\mathrm{H}$, Oh $\mathrm{H}$. A study on nursing students' elderly patient simulation experience. Journal of the Korea Academia Industrial cooperation Society 2013; 14 (7): 3358-3367.

56. Lambrinou E, Sourtzi P, Kalokerinou, Lemonidou C. Attitude and knowledge of Greek nursing students toward elderly. Journal of nurse education today 2009; 29: 617-22. 